\title{
Research on Investment Decision of Start-up Company Based on POCD Framework - Taking Kindbody as an Example
}

\author{
Wenchong $\mathrm{He}^{1, \dagger}$, Xiuping $\mathrm{Li}^{2, \dagger}$, Yingtong Zhang ${ }^{3, *, \dagger}$ \\ ${ }^{1}$ School of Accounting, Tianjin University of Commerce, Tianjin, 300000, China \\ ${ }^{2}$ School of social sciences, University of Manchester, Manchester, M139PL, the United Kingdom \\ ${ }^{3}$ School of management, Guangxi University for nationalities, Nanning,530000, China \\ *Corresponding author. Email: guanghua.ren@gecacdemy.cn \\ These authors contributed equally.
}

\begin{abstract}
The study of a more efficient and more general project investment feasibility evaluation system can effectively reduce the uncertain and unknown investment risks in the process of project investment evaluation and decision-making. We put forward an investment system -- POCD, which is suitable for the characteristics of start-up enterprises. It can capture the information of start-up enterprises more comprehensively and effectively to realize the evaluation of their investment value. In addition, this paper takes Kind Body, a start-up enterprise in the medical industry, as an example to explain how to use POCD. The analysis results show that Kind Body is an enterprise with great investment value. To be specific, Kin Body has an elite leadership team, outstanding industry first-class clinicians and research and development talents, as well as an advanced business strategy model. Meanwhile, with the help of opportunities from customers' demands for reproductive assistance and the steady development of the national economy in the United States, As well as the leap-forward level of infrastructure construction in the field of reproductive health science research and the inherent advantages of the stable social and political situation, Kind Body has proved to have excellent investment prospects. However, there are still deficiencies in the aspects of enterprise cost management, coordinated allocation of human resources, and research and development of competitive product portfolio model, which there are also areas where Kind Body needs to be continuously improved in the future to enhance the value of the enterprise. In general, Kind Body is worth investing in for investors.
\end{abstract}

Keywords: POCD framework, Kind Body, Start-up, Investment decision.

\section{INTRODUCTION}

In recent years, the physiological health of female has attracted more and more attention, while the medical industry was growing at an astonishing rate in the United States. Based on this phenomenon, an increasing number of medical companies that focuses on women's health have been established. Kindbody, a startup American women's medical company, has developed rapidly since it was established. As a startup company, Kindbody was established in 2018, which means its information is incomplete and valuations are immature. but it is still significant for evaluating the newly established companies like Kindbody. When judging whether different types of projects have investment value, the correct reference system of relevant investment feasibility evaluation can provide positive guidance for investors' investment judgment and bring into play the effect of getting twice the result with half the effort. However, a fixed reference system for investment feasibility may not always match projects of different species types. Therefore, it is particularly important to develop a universal evaluation system, and this paper adopts the POCD framework, a model designs specifically for startups, and could provide a comprehensive assessment of them with incomplete information, to study this company and conduct research. Then the investors could analyze based on the POCD framework and decide whether or not to invest in the startup companies. 
This framework is consequential because it contributes to the existing literature, making the literature associated with this model becomes more ample and rich. Also, more information is available for the investors when they do analysis, which helps them make more accurate judgments, and the investment decisions of VC has reference and reference significance. Furthermore, this research could also help the startup companies know clearly about their role definition, and the aspects and details of improvements that they need to focus on.

\section{METHOD}

In the POCD framework, there are four dynamic components of any entrepreneurial process or venture which are people, opportunity, external context, and deal. In the dimension of people, the definition given by the framework is those individuals or groups who perform services or provide resources for the venture, whether or not they are directly employed by the venture. It include Internal stakeholders such as founder, managers, employees, accountants, etc., and external stakeholders such as capital providers, suppliers, etc. By opportunity, the definition refers to any activity that requires an investment in a scarce resource in the hope of future returns. By context, the definition is meant all those factors that influence the outcome of the opportunity but are usually outside of management's direct control. Examples of contextual factors include interest rate levels, regulations, macroeconomic activity, and some industry variables such as the threat of substitutes. Finally, the definition of a deal describes the set of implicit and explicit contractual relationships between an entity and all resource providers. Examples of transactions range from contracts with capital providers to the terms of employment of managers. However, limited by startup disclosure data, deal are generally not analyzed in a focused manner. So the paper focuses on the three dimensions of kind Body which are people, opportunity, and context.

\section{PEOPLE}

Internal stakeholders

\subsection{CEO/Founders: Gina Bartasi}

To summarize Gina Bartasi basic information, she is a seasoned entrepreneur and veteran problem solver with 20+ years of experience in health tech. After founding Progyny (NASDAQ: PGNY) in 2015, based on employers' feedback and industry insights, Gina launched Kindbody in August of 2018.

\subsubsection{Advantages}

After reading Gina Bartasi basic information, her rich experience and well-known is attractive which is the two most significant and indispensable qualification in a start-up company. Rich experience will bring not only a lot of medical talents and a lot of funds, but also a large number of past customers and suppliers, which make the company's scale rapidly expand and occupy a large market share. Also, the past suppliers and investors she bring will Reduce the initial marginal cost and financial risks, respectively. Moreover, the research of Akitsu \& Hitoshi [1] show that start-ups reach their break-even point faster when their founders have had work experience in the same industry. This means that the debt Solvency Risk of the enterprise is reduced, and the debt raising ability is increased. Besides, because Kindbody is a high-tech female reproduction company, it needs a lot of R \& D investment. Ran [2] hold a view that a founder who have technical background will pay more attention to the cultivation of enterprise $R \& D$ personnel, which enhance the output efficiency of R\&D personnel, and improve enterprise innovation efficiency. In term of well-known, the research of Myra [3] Verify that successful venture founders have two characteristics: they are "known" and they "know." First, they know the key suppliers, the customers, talented individuals, and the competitors. At the same time, they are known in the industry, which means suppliers, customers, and employees are willing to work with them in spite of the obvious risks of dealing with a new company.

\subsubsection{Disadvantages}

It's very common for a start-up company to have its founder as the CEO. However, the functional conflict between the two roles cannot be ignore. She is like the only backbone of the Kindbody, once she is unstable, it will lead to a sharp increase in all risk, especially financial risk, and a continuous decline in profits, and even the bankruptcy of the company. Furthermore, the research of ran [4] suggest that the founder as the CEO with high shareholding will inhibit corporate innovation output. It may bring a fatal problem to the company because Kindbody is a high-tech medical company, low innovation leads to lower competitiveness. And for another problem is her Poor management style may not adapt to the rapidly changing whole medical industry environment. Zhang [5] demonstrate that the company's performance is often deeply affected by the founder's business philosophy. Thus, an unchanging management style may eventually lead to communication inefficiency between her and employees.

\subsection{Managers}

Kindbody has a highly integral management system, which includes six key managers. Since Kindbody is a 
start-up high-tech female reproductive healthcare company, the choice of CFO and CTO is most important for the company's development. A brief introduction to Richard, the CTO, who has been in the software industry for 25 years, has extensive experience leading engineering teams, driving product development, and strategy, and has expertise in technology mergers and acquisitions. And about Meredith, CFO, who has been one of the most visible female analysts on Wall Street, earning recognition from Fortune Magazine as one of the "50 Most Powerful Women" and from Time Magazine as one of the "100 Most Influential People in the World" (2009).

\subsubsection{Advantages}

As far as Kindbody's management is concerned, the most important advantage is that all managers have countless experience and resources in their respective fields. In terms of CTO, for example, in such a constantly changing medical technology industry, Kind Body have a strong CTO with his team, which not only reduce the risk of technological backwardness but also increase medical technology innovation and overall company competitiveness. Besides, His experience in M\&A is conducive to Kindbody's future structural integration or improvement of capital structure. In respect of the CFO, Whitney's experience as a dynamic, data-driven, and highly quantitative $\mathrm{CFO}$ will enable Kindbody to accelerate its already rapid growth and quickly seize the blue ocean market of female reproductive medicine. Another advantage to highlight about Kindbody is that they have a very powerful corporate culture, which is very difficult for a startup to achieve. Startups are more focused on their corporate hard power such as profit margin, ROI, ROE, etc., and less on their soft power such as CSR, culture, ethics, etc., but Kindbody has done this very well! Their corporate culture is "we are kind, we are open minded, we work hard and get it done" This corporate culture, illustrates the three most important qualities of the healthcare industry, which is very much in line with the corporate strategy of the healthcare industry. The graph of Corporate culture and profitability present information that the more aligned a company's strategy is with its culture, the higher the company's profitability. Kindbody should be located in a "culture aligned with strategy," which and have a 9.3\% profit margin and kindbody still has the opportunity to rise to a higher stage to improve its profit margin. Moreover, this strong culture enhance Kindbody brand value and goodwill and Increase social visibility, which can lead to attracting more new investors and new customers. Besides, it can also Strengthen company cohesion. Furthermore, the research of Putilova \& Shutaleva [6] present that the formation of the corporate culture principles contributes to raising the level of staff involvement, its labor activity performance, maintaining and reproduction of human capital assets of an enterprise.

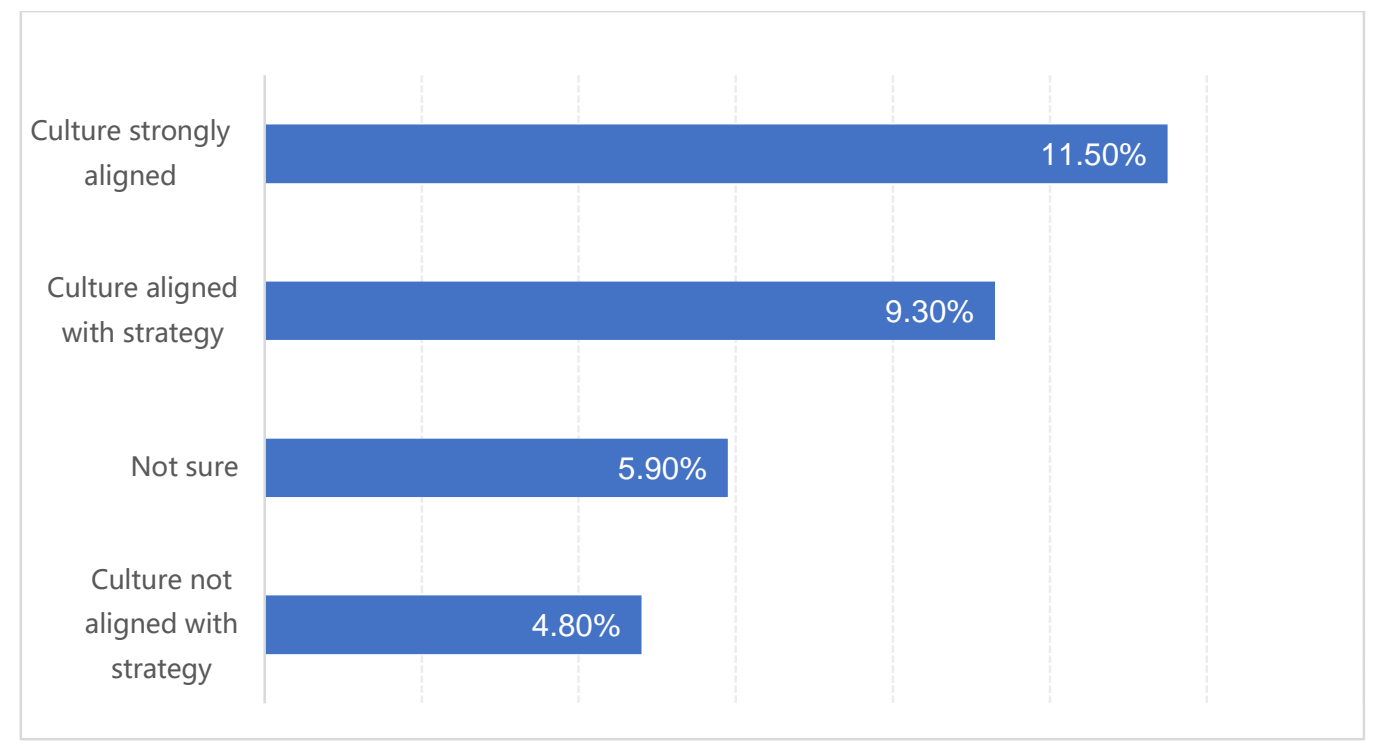

Figure1. Corporate culture and profitability Source: Right culture can double corporate profitability

\subsubsection{Disadvantages}

The managers are experienced in their respective fields, however it is important to mention that they all lack experience in the healthcare industry. For example, the CTO has to combine the reproductive industry with the computer industry by learning upfront, which not only leads to high marginal costs but also to a longer lifecycle of the entire program. Also, this does not signal well for the next round of investors, as time cost is an important decision factor for a venture capitalist, 
so they may abandon their investment. There are also some problems common to the industry that need to be mentioned, the management and their team or employees, the average age of all of them is high, the graph of U.S Physicians workforce by age the average shows that employee in the medical industry is around
50 years old, partly because the medical industry requires a long period of experience, but butHowever, this will also bring certain problems to the company, such as a decline in the efficiency and innovation of employees, the company has a high turnover of employees.

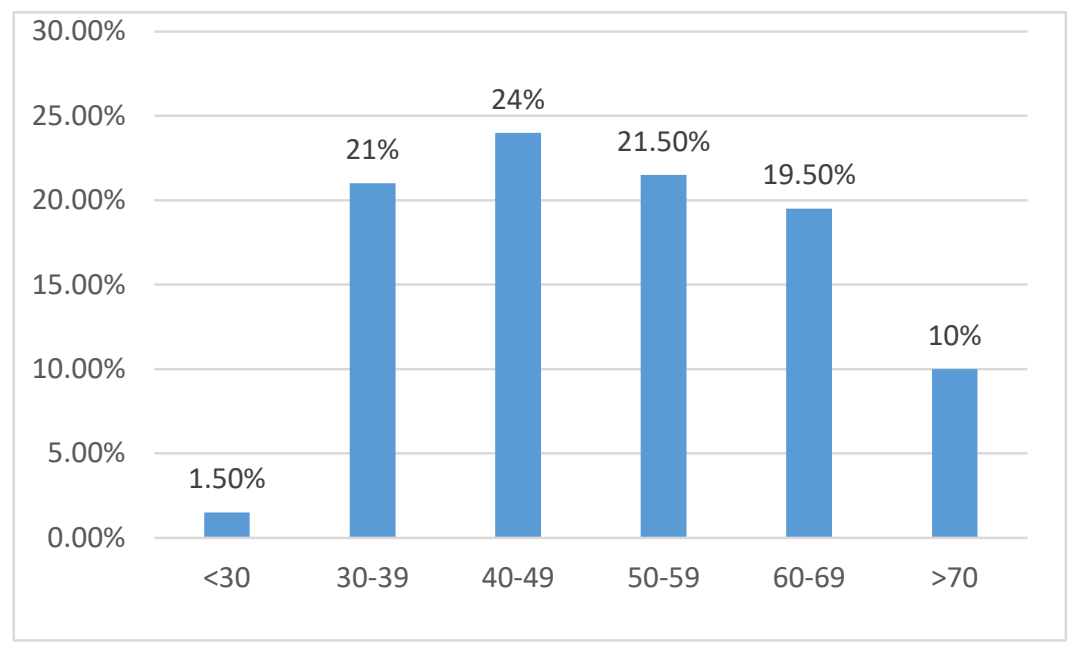

Figure2. U.S Physicians Workforce by age Source: Age Of Physicians By Specialty

Also, the average salary of these management and staff is also very high, the chart presents the information about the average salary of women's health in the medical industry is $312 \mathrm{k}$. In contrast, the average salary of people in the United States in 2020 is only $94.7 \mathrm{k}$. The salary of the medical industry is three times the average salary in the United States, which is extremely scary. And since startups are facing capital constraints and hiring quality management and staff is a necessity, this is a huge challenge for Kindbody's sustainability

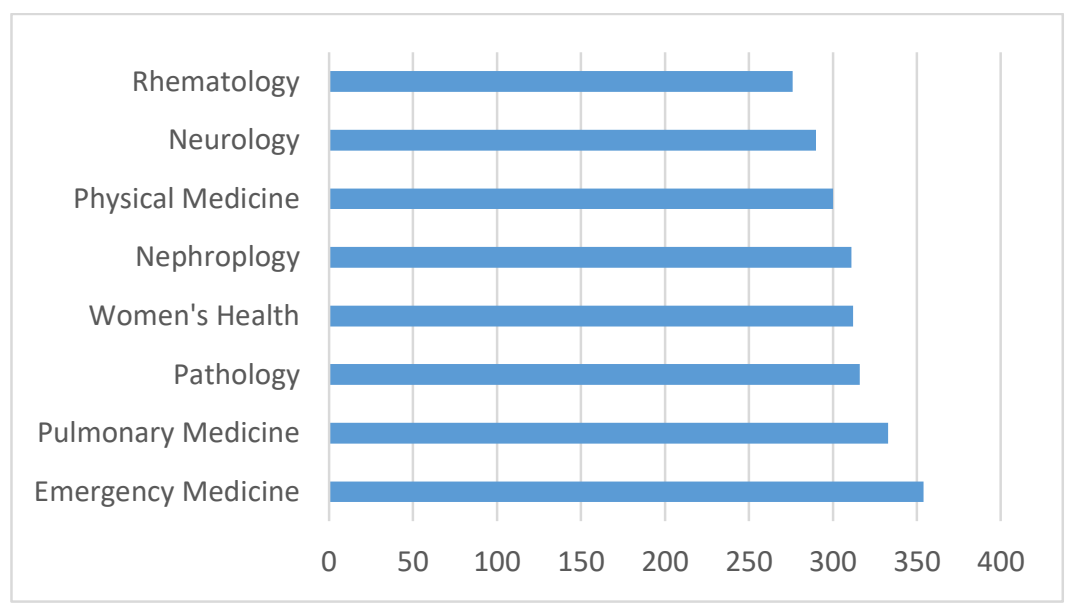

Figure3.Average Annual(K) Physician Compensation

Source: Physician salary report 2021: Compensation steady despite COVID-19

External stakeholders

\subsection{Investors}

To summarize Kindbody's funding history, Kindbody has raised a total of $\$ 63.3 \mathrm{M}$ in funding over 5 rounds. Their latest funding was raised on Jul 8, 2020, from a Series B round. Kindbody is funded by 14 investors, including 4 leading investors. Brief introduction of two main leading investors, which is Perceptive Advisors and GV. First Perceptive Advisers is a privately owned hedge fund sponsor that finances the public equity markets across the globe which is Lead investors who invest Kindbody twice for a total of $\$ 47 \mathrm{M}$, occupying three quarters of total investment. Another leading investor is $\mathrm{GV}$ which provides seed, venture, and growth-stage funding to technology 
companies. And it has made 848 investments. Their most recent investment was \$60M on May 26, 2021.

\subsubsection{Advantages}

From the available disclosed data, it appears that both major investors have participated in reinvestment in Kindbody and their second investments are larger than their first and that both are companies that have sufficient capital to invest. This certainly enhances the probability of their reinvestment. Reinvestment will enable Kindbody to decrease the risk of bankruptcy, increase the life cycle and make medical technology innovation possible. In addition, more investors will take notice of Kindbody, and there may be follow-on investment situations, which makes it easier for the company to open branches. Moreover, Zheng[7] believe that Angel investment helps to improve the company's operating performance, significantly improves the company's profitability and growth ability, and also has a certain impact on the company's operating ability. I would suggest that more angel investment would make the above effect more obvious. However, the research of Mella-Barral [8] shows another perspective on this effect which he believes the investors could extract advantageous terms by threatening not to reinvest: the more accurate the incumbent, the more the signal sent by his non-participation to alternative financiers would be negative. The effect of this view is exactly the opposite of the effect I analyzed before, hence Kind Body how to balance the benefits and drawbacks of reinvestment is also essential.

\subsubsection{Disadvantages}

Firstly, equity dilution has always been one of the biggest headaches for startups and in the case of Kind
Body, existing investors only make the most basic equity investments without Ordinary Bond, convertible bond or preferred stocks. This situation with pure equity found will cause a high cost of capital which lead to high cost and financial risk when Kindbody finance the next round. Besides, Zhang[9] hold a view from its research that Narrow and single external financing channels are difficult to meet the long-term strategic development of small and micro enterprises, which has become a major constraint. Secondly, because A large amount of equity have been diluted, Kind Body have less Retained \%ownership which reduces the likelihood of new investors investing. Also, most private healthcare companies such as Kindbody are asset-light companies because most of their fixed assets, i.e., medical equipment, are leased. The research of GUI[10] indicates that as a "light asset" start-up, less fixed assets, less products, intangible assets are generally not easy to be evaluated and recognized, which greatly affects the equity financing of enterprises. This, in turn, makes it more difficult for them to raise funds.

\section{OPPORTUNITY}

\subsection{Competition}

With the development of the medical industry, the competition is becoming fierce. Based on the statistics, the global women's health market size is expected to reach USD 47.8 billion by 2027 , according to a new report by Grand View Research, Inc., registering a CAGR of $4.9 \%$ over the forecast period [11]. Also, the women's health market in the U.S. has also shown a growing trend. The figure 4 illustrates the female's health diagnostics market size in the U.S. from 2014 to 2025. It reached 15.5 billion in 2017 and is anticipated to increase in the future

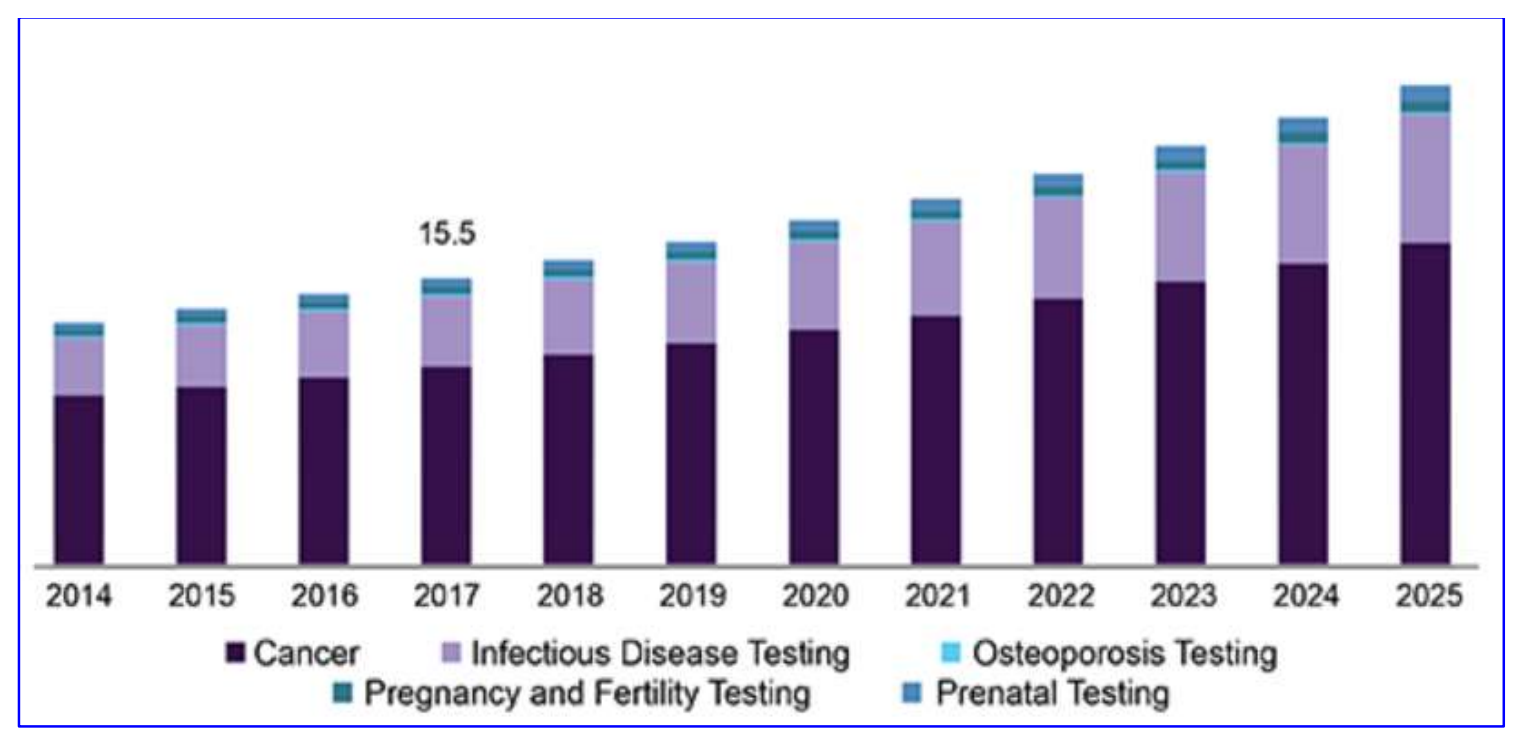

Figure 4. U.S. women's health diagnostics market size, by application, 2014-2025 (USD Billion) Source: Women's Health Diagnostics Market Size, Worth \$47.8 Billion By 2027 | CAGR: 4.9\% 
The four main competitors of Kindbody [12] are AIM Women's Wellness Center (AIM) [13], Cicero Diagnostics (CD) [14], and Nuelle ${ }^{\mathrm{TM}}$ [15]. AIM focuses on the patients' reproductive health by considering the underlying casus of their conditions and issues. While the $\mathrm{CD}$ is a women's health care company, which is devote itself to the clinical assays for understudied female's infertility. Also, Nuelle $\mathrm{T}^{\mathrm{TM}}$ is a women's personal health company, which specializing in delivering solutions for women's sexual wellbeing.

Table 1. the companies' primary services, service items, and establishment years

\begin{tabular}{cccc}
\hline & Primary services & Service items & $\begin{array}{c}\text { Establishment } \\
\text { years }\end{array}$ \\
\hline $\begin{array}{c}\text { AlM Women's } \\
\text { Wellness Center }\end{array}$ & reproductive health & $\begin{array}{c}\text { preconception; egg quality; male } \\
\text { fertility; pregnancy support; IVF \& IUI } \\
\text { support, etc. }\end{array}$ & 19 \\
$\begin{array}{c}\text { Cicero } \\
\text { Diagnostics } \\
\text { Kindbody }\end{array}$ & female's infertility & ReceptivaDx & 7 \\
whole-body wellness & $\begin{array}{c}\text { LGBTQ; fertility assessment; egg } \\
\text { freezing; gynecology; IVF conception } \\
\text { care; Kindbody 360: holistic care } \\
\text { Fiera }{ }^{\mathrm{TM}}\end{array}$ & womersonal Care Device & 3 \\
& wellbeing & $8-9$
\end{tabular}

By comparing Kindbody with these competitors, it has its own benefits and drawbacks in various aspects.

\subsubsection{Advantages}

The advantage of kindbody is that it provides a wider range of services, including fertility assessment, egg freezing, gynecology, and so on. Thus, the customers have more choice if they choose kindbody, and they could enjoy the one-step service, which is more convenience..

However, if the customer chooses to go to the CD, they can only enjoy a single type of services, such as the treatment of infertility. Similarly, the targeted service of Nuelle $^{\mathrm{TM}}$ is sexual wellbeing. customers without sexual issues might not choose this clinic. The figure 4 illustrates these companies' primary services, service items, and establishment years. It is apparent that the service items of AIM and Kindbody are more extensive than the CD and Nuelle ${ }^{\mathrm{TM}}$. In a word, Kindbody and AIM are general clinics, while some of its competitors are specialist clinics. Thus, the female could get one package of services in the Kindbody. As there are more types of services in this company, customers also have a wider range of choices, which is beneficial for the company to expand customer groups. Distinct types of customer sources can help Kindbody grow rapidly in both various fields.

\subsubsection{Disadvantages}

Although Kindbody cares whole body wellness of female, it's not extreme professional in one direction or another, which is also the drawbacsk of general clinics. Compare with CD, Kindbody's service like test-tube baby is not professional enough. $\mathrm{CD}$ has a special test: RecptivaDX, which represents a novel generation of testing to detect defects on the uterine lining responsible for unexplained infertility, implantation failure, and recurrent pregnancy loss. It specializes in infertility and has a high profile in this industry to help female address the fertility problems. Obviously, Kindbody has neither the technologies nor the reputation as the CD in this aspect, which becomes one of its disadvantages during the process of development.

In addition, according to figure 4, Kindbody was only established for approximately 3 years, while the AIM has established 19 years, which was almost 6 times. There is no denying that AIM has a base customer group and regular customer, but Kindbody does not have. If Kindbody wants to achieve its goals, the customer base cannot be ignored. Also, the competition in this industry is fierce, it's clear that the most significant issue for startup companies are survive. Does Kindbody, such a young company, be able to survive in such a fierce environment? Both the internal and external stakeholders should pay attention to this issue.

\subsection{Customers}

\subsubsection{Advantages}

To begin with, Kindbody has a larger customer base due to its scope of services. When other clinics only pay attention to a single field, Kindbody has already 
establish its relatively complete system to help women who have the gynecological problems. For instance, the $\mathrm{CD}$ only focus on the women with infertility, but the Kindbody focus on different aspects of gynecological issues. It is apparent that a wider range of services means a wider range of customers, thus the Kindbody has larger markets than others. According to the European Shoppers Insight Report [16] conducted by data provider IRI, a wide product range is crucial to attracting consumers. In this study, 2,600 shoppers are required to evaluate each store based on some features, including: innovation, quality, and shopping experience. The result clearly shows that the stores with a wide range of products are more popular with customers, because $56 \%$ among the experimental subjects choose one store because of the wide variety of products. Thus, it could be estimated that the number of customers for Kindbody is favorable in the medical industry. With more consumers, this business is easily to get more revenue and profits, which is one of the most essential things for the startup companies. Because the startups need the funds to survive and develop, and getting profits in a short time could establish confidence for both the managers and the investors, so that it helps Kindbody to raise capital and finance better.
Furthermore, Kindbody has both online services and offline clinics, while the competitors do not have. On the one hand, the online fertility consultation service of this company provides consumers with intimate services. Including the exclusive design of health care for the women who want to fully understand their reproductive health; one to one consultation with fertility experts through video conferences;, 60-minute fertility rate assessment service, etc. If female have any questions about the gynecological disease, it is unnecessary for them to go to go to the hospitals or clinics, staying at home will be adequate to enjoy these services. Kindbody has professionals responsible for online communication and consultation, while most of its competitors do not offer the impeccable online services. This channel gives the Kind Body a huge advantage during the epidemic. In 2020, although some areas in the U.S. begun re-opening, the stores were untoward to return to normal operations as before in the case of an COVID19 epidemic [17]. Thus, it is significant for them to establish and develop the online services, and it is one of the reasons why an increasing trend of companies start to focus on the online business.

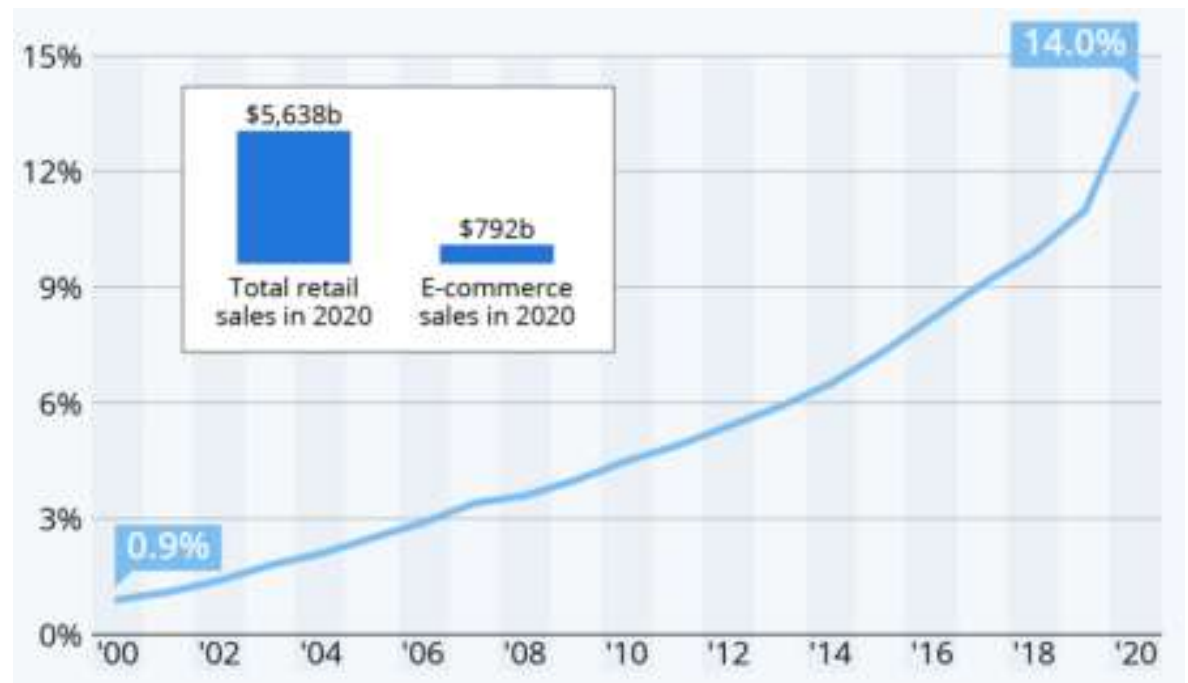

Figure 5. Pandemic accelerates the shift to online retail, E-Commerce sales as a percentage of total retail sales in the United States

Source: Statista: Pandemic Accelerates Shift to Online Retail

*Not seasonally adjusted; excluding food services sales

Figure 5 gives some information about the pandemic that accelerates the shift to online retail. The blue line, which stands for the E-Commerce sales as a percentage of total retail sales in the United States, has shown an increasing trend between 2000 to 2020 . It grew from $0.9 \%$ to $14 \%$, almost 14 times throughout this period. When other businesses started to consider online service models, Kindbody has already had the mature online service system, which is its advantage compares with others.

On the other hand, offline service is also the focus of this company. It has 7 office locations across America, incorporating Atlanta, Princeton, Austin, Los Altos, and so on, and the headquarter is in New York. By established multiple divisions in multiple regions, Kindbody quickly attracted customers from these 
regions in the U.S. Also, its offline services are also intimate and convenient, so that the number of customers has increased significantly in recent $t$ years.

In a word, Kindbody's intimate service could improve customer satisfaction and also improve its reputation.

\subsection{New ideas of service strategy}

\subsubsection{Advantages}

Kindbody has the novel service model like the Kindbody mobile clinics and Fertility Bus, which is a strategy to attract customers. When female walk into the streets, the yellow bus with a novel design could attract their attention rapidly. In these mobile clinics and bus, women can undergo anti-Müllerian hormone (AMH) tests to assess their ovarian health and also obtain a complete fertility assessment and the recommendations from the professional doctors. Moreover, it's also a fabulous way to make the advertisement for this company. Mobile advertising and services enhance the communication of the brand and visibility, allowing more female to experience the company's services, which provides The Kind Body with the possibility of increasing customers. According to Mobile health clinics in the United States [18], mobile health clinics are essential in providing care to some of the vulnerable populations. Based on the research and calculation, the mobile clinics have to provide approximately 3500 visits annually, and more than half of them are female (around 55\%). It indicates that the female is one of their main customer groups and have play a crucial role in this industry. What's more, by researching target populations of the clinics (Figure 6), people who require the LGBTQ occupies about $14 \%$, the uninsured people even account for $56 \%$, which is the largest group. However, one of the Kind Body's main services is LGBTQ, so that this company has ability to use the mobile clinics to serve these groups. Also, Kindbody has created a platform where could provide care to anyone, whether the patients have insurance or not. By doing so, Kindbody's mobile clinics can be used as a special service to catch the $70 \%$ target customers $(14 \%$ for LGBTQ and $56 \%$ for uninsured people) and then develop. It is the opportunity for a startup company to expand its customer base.

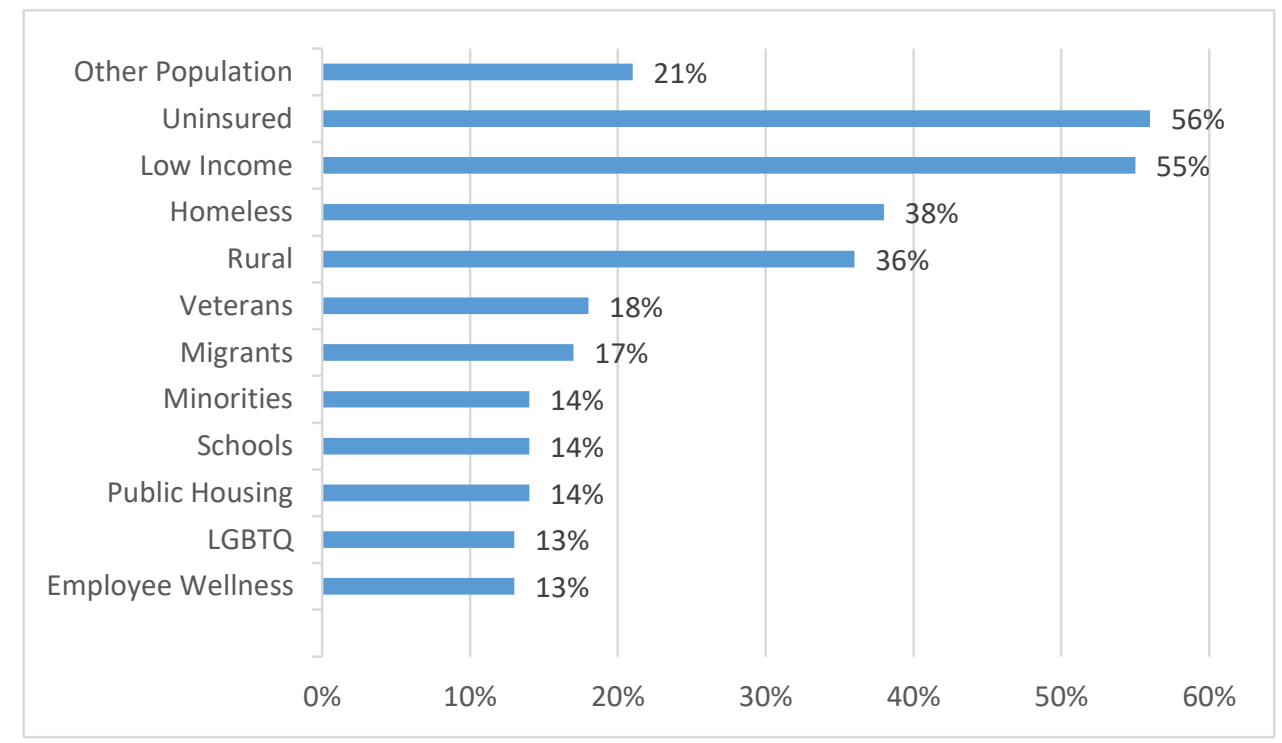

Figure 6: Mobile health clinics in the United States [18] Mobile Health Clinics Affiliations. 286 clinics report on the affiliations or parent organizations.

*Clinics may designate multiple affiliations

\subsubsection{Disadvantages}

However, this approach consumes manpower and material resources, which means it will increase the burden for both company and investors. Both the mobile clinics and fertility bus cost huge capital, which might cause a big pressure to the Kindbody's cash flow. In other word, whether this company's cash flow can meet its day-to-day expanses should be taken into consideration. As the manpower and material resources spending too much, the investors might not be willing to invest it, which is not beneficial for the startup companies.

What's worse, the barriers of mobile clinics still persist [18], especially for the populations who live in resource-limited areas. The numbers of mobile clinics are limited, which might impact the quality and quantity of service, so additional work needs to be done for Kind 
Body in order to advance the availability of this significant resource.

\section{CONTEXT}

According to the analysis of the macro environment for strategic decisions, to a great extent, it can avoid the influence of subjective and one-sided thought management. It can also make the enterprise management strategy more practical for an enterprise to discuss the uncertainty of the future environment, clear the development direction of the future environment, prepare for and to plan ahead of time, give full play to the enterprise business vigor, create favorable conditions, actively improve the enterprise environment.

\subsection{Economics}

Economic, environmental factors refer to the social and economic conditions and national economic policies that constitute the survival and development of enterprises [17]. A country's overall economic development level decides the life duration and degree of development of enterprises. The influence of the performance of the economic environment of enterprises is more direct and specific. In general, the economic environment and active efforts to enterprise's the production and management have a more sensitive reaction, improve the economic environment is stable, is directly restricted by the overall national level of economic development. Among them, the overall level of national economic development comprises five factors, such as economic aggregate, economic structure, economic speed, economic efficiency, and economic characteristics, which are all measures of the overall level of national economic development. The level of national overall economic development and the state of economic environment influence each other and contribute to each other [18].

\subsubsection{Advantages}

The US GDP and the size of the healthcare market have shown a good and steady growth trend and will continue to grow steadily and appreciably in the coming years. The high level of overall economic development and the active economic environment promote the continuous expansion of the market demand capacity in the field of medical reproduction [19]. In addition, it also enables enterprises to have a shorter investment recovery period in addition to the attraction of the huge market demand scale, and the company's operating quality also gets better performance. The proportion of productive investment keeps rising, while the proportion of non-productive investment keeps declining [20]. New elements are concentrated in the development of more core competitive businesses. The core businesses are transformed from single product results to horizontal and vertical dual dimension simultaneous deep development, forming the portfolio of core competitive products and thickening the moat of enterprises. This will also promote the continuous automatic adjustment of internal labor resources, more balanced labor leverage, and gradually balanced human resources allocation.

\subsubsection{Disadvantages}

The steady growth of economic development also brings some contradictions and blows to the interests of enterprises. Rising peripheral costs conflict with maximizing profits pursued strategically by start-ups. With the gradual maturity of social economy development, more and more workers paticipate in social wealth distribution. The enterprise must pay the labor remuneration, procurement, production also gradually increase, capital reserves instability, and the high cost of using funds in real time with the development of the start-ups. The containment of a good economic environment will inevitably to start-up existence is also a challenge. In addition, the processing cost of primary processed products keeps rising, and the stability of the change in the position and income of the supply chain keeps shifting. The prices of basic materials, agricultural products, food, medical drugs, and other products keep rising, and the price fluctuations of fuel and other primary products are still unstable [21]. Therefore, the cost consumption of enterprises continues to increase, especially the weakening of the economic benefits of start-ups is more intense.

\subsection{Politics}

The political environment manifests a country or region's political system, policies, laws, and regulations. Constitute a specific political environment factors include: the overall national development route design, local specific principles, and policies, etc., but precisely these factors of political environment often are also restrict and affect the performance of the enterprise, especially the start-up enterprises to obtain long-term investment behavior, but also have relevant links between political environment and restriction.

\subsubsection{Advantages}

A stable political environment gave birth to sound, neat, and good elastic consumers. And the market has a more balanced supply and demand [22], The consumer market has a new type of consumer demand, creates more new consumption pain points are need to constantly, coordinates enterprises to actively participate in market oriented product development and the transformation and upgrading of its strategic direction. 
Take Kindbody as an example. Within a short period of time, the company has completed multiple product lines within a short period and constantly raised the threshold for cooperation with suppliers [23]. The suppliers in cooperation with it have excellent qualifications, first-class authority certification in the industry, stable supply capacity, and a perfect supply level. Therefore, the product research and development content of Kindbody includes both market-oriented service products and some product-oriented service products, providing more care and help for patients with diseases and constantly reshaping the corporate reputation.

\subsubsection{Disadvantages}

With the constant stability of the political environment, the quantity and quality of information circulating in the market increase sharply. The utilization cost and utilization barrier of high-quality information increase gradually. With the overall level of science and technology and the continuous increase of competitors' characteristic science and technology projects, the utilizable cost of high-quality information in the market increases gradually.

\subsection{Technology}

The Technology environment refers to the elements of science and technology in an enterprise's environment and is directly related to the elements of a collection of all kinds of social phenomena, including national science and technology system, science and technology policy, technology level, and development trend of science and technology, science and technology, environmental change of enterprise's production and sales activities have a direct and significant effect, especially in the face of a severe shortage of raw materials, energy today. Science and technology have often become the key to human destiny and social progress.

\subsubsection{Advantages}

As the development trend of reproductive assistance technology is gradually stable and mature in the scientific and technological production environment, in the industry's overall scientific and the technological level is steadily rising. Kindbody is also constantly committed to giving back the trust of users with high-quality services and products, thus greatly increasing the cure rate and sense of cure experience for users with the best core research and development strength of the enterprise. The supporting process of related functional areas is transparent, perfect, and efficient; Adequate research and development personnel; Complete technical instruments and facilities, and necessary auxiliary facilities.

\subsubsection{Disadvantages}

the product line and product portfolio field configuration strategy need to be improved; the target customers of the product line are too targeted; the product line should be extended, the product category should be expanded, and the product mix should be optimized [24, 25].

\section{CONCLUSION}

This paper analyzed whether kindbody is worth investing in from capital investors based on a POCD framework. By using a large number of statistics and information come from the related articles and Kindbody's websites. In summary, this paper found that: Firstly, kindbody has excellent and well-known founders, resourceful and dedicated management, and investors who have a high chance of reinvesting. Secondly, kindbody has strong competitiveness with its large customer base and a new ideal of service strategy. Thirdly, the context of the health market in the US is rapid growth. It showing a trend of continued growth in the future, which add unlimited potential to kindbody development.

Although each of the three dimensions has some issues that cannot be ignored, Venture Capital investors will believe that its advantages could cover the disadvantages. Therefore, they will be optimistic about Kindbody's prospects and consider kindbody a worthy investment. In addition, this study also demonstrates that the POCD framework does provide efficiency and accuracy when analyzing startups. These findings could be good references for those who intended to qualitatively analyze a startup to determine if it is worth to invest in or not. Future research should be devoted to the development of quantitative analysis without extensive disclosure of information and how to efficiently combine quantitative analysis and pocd framework to provide investors with applicable models.

\section{REFERENCES}

[1] Oe,H.Mitsuhashi,Founders' experiences for startups' fast break-even,Vol.66,no.11 Journal of Business

Research,2013,DOI:10.1016/j.jbusres.2012.01.011.

[2] R.Maojuan,Research on the Influence of founder CEO on the company's innovation efficiency,Southwest University of Finance and Economics, MA thesis.2019,Available at:https://kns.cnki.net/KCMS/detail/detail.aspx?dbn ame $=$ CMFD202002 \&filename $=1019642689 . \mathrm{nh}$

[3] R.Maojuan, Research on the Influence of founder CEO on the company's innovation efficiency,Southwest University of Finance and 
Economics, MA thesis.2019,Available at:https://kns.cnki.net/KCMS/detail/detail.aspx?dbn ame $=$ CMFD202002 $\&$ filename $=1019642689 . \mathrm{nh}$

[4] M.Hart,Some Thoughts on Business Plans,Harvard Business School.No.9-897-101.

[5] Z.Yuncheng, Research on the influence of Founder's business philosophy on the company's performance: a case study of Fuyao Glass, Vol 201,no.11,China International Finance and Economics (English and Chinese),2017, DOI:10.19516/j.cnki.10-1438/f.2017.11.163.

[6] E A.Putilova,Putilova.E A,Shutaleva.A $\mathrm{V}$,Corporate culture as one of the key factors of effective industrial enterprise development, Vol.966, no.1IOP Conference Series: Materials Science and Engineering, 2020, doi:10.1088/1757-899X/966/1/012132

[7] Z.Chunhua, Research on the impact of angel investment on Corporate Governance, Hefei University of technology, 2015, DOI:10.7666/d. Y2925696

[8] Mella-Barral Pierre,Strategic decertification in venture capital,Vol65,Journal of Corporate Finance,2020,DOI:10.1016/J.JCORPFIN.2020.101 724.

[9] G.Ziqing,C.Xiaoyan, Analysis of financing channels for start-ups, no.9,New financial world,2020, pp65-66,Doi: 10.12324/j.1674-5221.0200.09.041.

[10] Z.Limin,L.kaixu,Research on the financing of small and micro technology enterprises in the start-up period, no.10, Mall Modernization, 2016, DOI:10.14013/j.cnki.scxdh.2016.10.130.

[11] "Women'S Health Market Size Worth \$47.8 Billion By 2027". 2021. Grandviewresearch.Com. https://www.grandviewresearch.com/press-release/ global-womens-health-market.

[12] "Kindbody - Fertility Clinic, IVF, Egg Freezing And Gynecology". 2021. Available at: Kindbody. https://kindbody.com/.

[13]"Women's Wellness \& Fertility LA County - AIM Women'S Wellness Center". 2021. AIM Women'S Wellness Center. Available at: https://aimwellnessclinic.com/.

[14] "Cicero Diagnostics". 2021. Cicerodx.Com. Available at: https://cicerodx.com/.

[15]"Nuelle-Exploramed". 2021.Exploramed.Available at:https://www.exploramed.com/nuelle.

[16] B. Becky. A Wide Product Range Is Crucial To Attracting Consumers In-Store.2021, Cosmeticsbusiness. Com. Available at: https://www.cosmeticsbusiness.com/news/article_p age/A_wide_product_range_is_crucial_to_attractin g_consumers_in-store/135928.
[17] R. Craig. "The Benefits Of Ecommerce: How Selling Online Is Helping Businesses Survive COVID-19". 2020, Truecommerce. Available at: https://www.truecommerce.com/blog/ecommerce-b enefits-during-covid-19.

[18] Malone, Nelson C., Mollie M. Williams, Mary C. Smith Fawzi, Jennifer Bennet, Caterina Hill, Jeffrey N. Katz, and Nancy E. Oriol. 2020. "Mobile Health Clinics In The United States". International Journal For Equity In Health 19 (1). doi:10.1186/s12939-020-1135-7.

[19] Barattieri Alessandro, Moretti Laura,Quadrini Vincenzo,Banks funding, leverage, and investment,FinancialEconomics, Volume141,2021, PP148-171,Doi:https://www.sciencedirect.com/scie nce/article/abs/pii/S0304405X21000830

[20] Gong Changrui,The Impact of the New Global Epidemic on China's Macro Economy and the Analysis of Regulatory Policies,International Journal of Frontiers in Sociology, Volume 3, 2021,Doi:https://schlr.cnki.net/zn/Detail/index/W WMERGEJLAST/SJIW1D84998D0E0B81AEF48 A15A5386FD080

[20] A Kyriazis Nikolaos, Trade Policy Uncertainty Effects on Macro Economy and Financial Markets: An Integrated Survey and Empirical Investigation, Risk and Financial ManagementVolume 14, 2021,

41-41,Doi:https://www.mdpi.com/1911-8074/14/1/ 41

[21] Stankov Petar,The Political Economy of Populism:An Introduction, Taylor and Francis, 2020,

Doi:https://www.taylorfrancis.com/books/oa-mono /10.4324/9780429355691/political-economy-populi sm-petar-stankov

[22] Mohn Klaus, The gravity of status quo: A review of IEA's World Energy Outlook,

Economics of Energy \& Environmental Policy, Volume 8, 2019, Doi:10.5547/2160-5890.8.2.kmoh

[23] Zhang Tianyi,Seasonal Adjustment of the Consumer Price Index,social science,Volume 5, 2017,PP 5-15,Doi:10.4236/jss.2017.53002

[24] M. N. G. Omofa,An Empirical Investigation into the Effect of Financial Sector Development on Consumption and Inflation in Nigeria: 1986-2012, Business and Management,Volume 5, 2016,PP 11-21,Doi:10.4236/OJBM.2017.51002

[25] Basu,Open Economy Macroeconomics of Credit, Employment and Growth: A Structuralist Approach ,Developing Areas, Volume 49, 2015. PP $135-150$ 